\title{
Tangential Fields
}

National Cancer Institute

\section{Source}

National Cancer Institute. Tangential Fields. NCI Thesaurus. Code C152035.

A two-dimensional (2D) array of opposing, oblique beams of external radiation. This approach is most often used in the adjuvant radiotherapy of breast malignancies. 